\title{
Taekwondo Nails: A Case Report and Review of the Literature on Sport-Related Nail Abnormalities
}

\author{
Isabel Cristina Valente Duarte de Sousa ${ }^{1 *}$, Antonella Tosti ${ }^{2}$ \\ ${ }^{1}$ Department of Dermatology, México city, México \\ ${ }^{2}$ Department of Dermatology \& Cutaneous Surgery, Miller School of Medicine, University of Miami, Miami, FL, USA
}

Received: April 29, 2016; Accepted: May 30, 2016; Published: July 01, 2016

*Corresponding author: Isabel Cristina Valente Duarte de Sousa: Department of Dermatology, Private practice, México city, México. E-mail: cristinavalente@me.com

\begin{abstract}
Nail abnormalities related to different sports have been described in the literature. In this article, we report the case of a male patient with nail abnormalities due to taekwondo and review the literature for sport specific nail changes. To our knowledge, this is the first article that describes nail abnormalities associated with taekwondo.

Keywords: Nail Dystrophy; Traumatic Nail Dystrophy; Nails and Sports; Taekwondo Nails; Onychodystrophy; Sport Related Nail Changes
\end{abstract}

\section{Introduction}

Sport related abnormalities of the nails are frequent because the nail plate, nail bed, nail matrix and periungual area experience significant amounts of pressure and trauma during these athletic activities [1-3].

Since the type of trauma differs with each sport, the nail changes are sometimes sport specific [1]. Toenails are more commonly affected in sports such as tennis, soccer, basketball, running, golf, gymnastics and dancing [1-4] while the fingernails are affected in karate, judo, golf and Frisbee $[3,8,9,10]$.

We describe the case of a male patient with nail abnormalities due to taekwondo and review the literature for sport specific nail changes. To our knowledge, this is the first article that describes nail abnormalities associated with taekwondo.

\section{Case Report}

A 38-year-old male patient had a 1-year history of nail dystrophy, thinning and cracking of the right index finger. He had no relevant past medical history. He denied any acute trauma to the nail and hands, but with direct questioning said that he practiced Taekwondo. He mentioned that during practice he performed backhand punches with the affected hand.

Physical examination showed onichorrhexis and severe brittleness of the nail of the right $2^{\text {nd }}$ finger (Figure 1). The other fingernails and the toenails were normal.

Dermoscope examination of the affected nail showed thinning and shortening of the nail plate with superficial scaling (Figure 2).

A diagnosis of nail matrix damage due to Taekwondo was made and the patient was instructed to avoid backhand punches during practice.

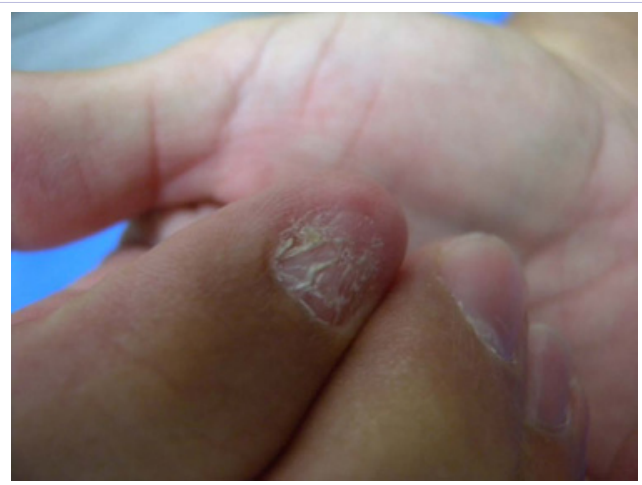

Figure 1: Second Finger of Right Hand with Onichorrhexis and Brittleness.

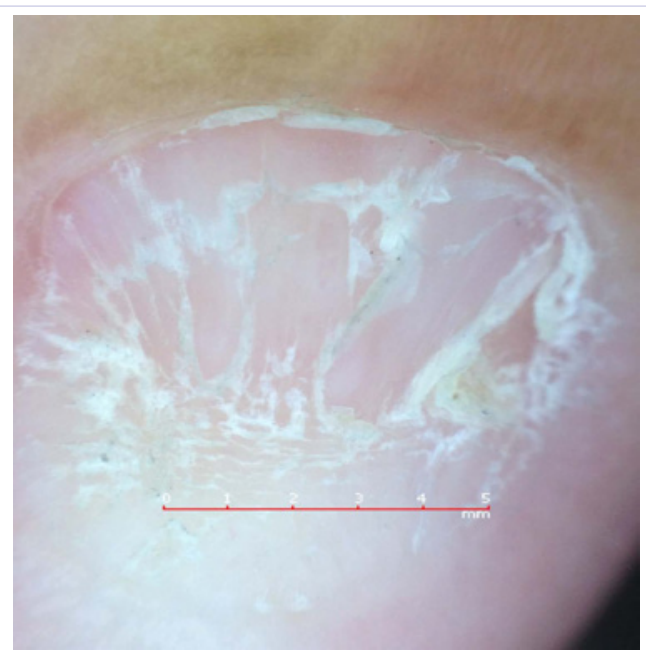

Figure 2: Dermoscopic image of affected nail plate shows thinning, shortening and superficial scaling. 


\section{Discussion}

The most common nail abnormality described associated with sport is the "Tennis toe". It consists of the appearance of a subungual hematoma generally affecting the hallux or the second toenail whichever is longer $[1,4,6]$. The injury is incurred due to the repeated trauma to the nail bed each time the toe contacts the inside of the shoe, as a result of abrupt stops on the tennis court $[2-4,6]$.

Subungual hematomas have also been reported in other sports where there is constant thrusting of the athlete's foot into the toe box of the shoe, such as squash, soccer, basketball, running and jogging $[1,2,6,8]$.

In runners and joggers (Jogger's toe) the $4^{\text {th }}$ and $5^{\text {th }}$ toes are more commonly affected and are accompanied by nail discoloration, onycholysis, proximal transverse ridging and erithema $[1,2,6]$. The $2^{\text {nd }}$ and $3^{\text {rd }}$ toes are generally affected in soccer and squash players [6]. Other nail abnormalities reported in soccer players include nail shedding, transverse ridging, onycholysis and even avulsion of the nail plate, caused by the impact force of kicking [1,2].

Professional dancers can have onychogryphosis and subungual exostosis [2] while rhythmic gymnasts present with lamellar splitting, splinter hemorrhages, dystrophia mediana canaliforme, transverse (Beau's lines), and longitudinal pigmented bands due to trauma to the nail bed and nail matrix [5].

Fingernail abnormalities have been reported in golfers, Frisbee players, karate and judo fighters. The "Golfer's nails" refers to the distal splinter hemorrhages that appear in the fingers used most strongly in the golf grip hand $[3,8]$.

Nail hemorrhage is common in Frisbee players due to the repeated minor trauma of the nail plate originated when catching the Frisbee [8].

Karate nails are due to the injury of the nail matrix as a consequence of the sharp strong blows and usually present as leukonychia $[3,9]$.

In Judo, trachyonychia due to the frequent grabbing of the opponent's jacket has been described $[3,10]$.
Taekwondo is a Korean martial art that means "the art of foot and hand" [11]. Although the legs are mostly used in the practice of taekwondo, there are some specific hand punches (the "backfist forward strike" and the "reverse punch") in which the dorsal aspect of the hand is used to give the blow [7]. During these movements, the nail plate, nail bed and nail matrix are exposed to trauma predisposing the patient to have trauma induced nail abnormalities.

A computerized search of Pub Med data base, as well as GoogleScholar, was performed using the terms "sports and nails", "athletes and nails", "onicopathology and sports", "nails in sports", "taekwondo nails" for papers published in English from January 1985 to the present. We were not able to find any paper describing the above-mentioned nail signs in taekwondo.

\section{References}

1. Adams BB. Dermatologic Disorders of the Athlete. Sports Med. 2002;32(5):309-321.

2. Adams BB. Jogger's toenail. J Am Acad Dermatol. 2003;48(5 Suppl):S58-59.

3. Baran R. Baran and Dawber's Diseases of the Nails and Their Management. ${ }^{3 r d}$ ed 2001. London. Blackwell Science. 2008;pp.333

4. Bergfeld W, Taylor J. Trauma, Sports and the Skin. Am J Ind Med. 1985;8(4-5):403-413.

5. Biolcati G, Berlutti G, Bagarone A, CAselli G. Dermatological Marks in Athletes of Artistic and Rhythmic Gymnastics. Int J Sports Med 2004;25(8):638-40.

6. Cohen P, Schulze K, Nelson B. Subungual Hematoma. Dermatol Nursing. 2007;19(1):83-84

7. Pieter F, Pieter W. Speed and Force in Selected Taekwondo Techniques. Biol Sport. 1995;12(4):257-266

8. Ryan AM, Goldsmith LA. Golfer's Nails. Arch Dermatol. 1995;131(7):857-858.

9. Scher RK. Ocupational nail disorders. Dermatol Clin. 1988;6(1):27-33.

10. Shelley WB, Shelley ED. A dermatologic diary. Portrait of a practice. Cutis. 1997;59(4):181-182.

11. Siana JE, Borum P, Kryger H. Injuries in Taekwondo. Brit J Sports Med. 1986;20(4):165-166. 